\title{
Nonlinear analysis of extreme snow fragility of reactor hall frame
}

\author{
Juraj Králik ${ }^{1, *}$, Alžbeta Grmanová $^{1}$ and Juraj Králik, jr. ${ }^{2}$ \\ ${ }^{1}$ FCE STU Bratislava, Department of Structural Mechanics, 810 05, Bratislava, Slovakia \\ ${ }^{2}$ Academy of Fine Arts and Design in Bratislava, 814 37, Bratislava, Slovakia
}

\begin{abstract}
This paper gives the results of the safety analysis of the nuclear power plant structures in Slovakia in case of the extreme climatic loads. The linear and nonlinear analysis of NPP structures with the reactor VVER $440 / 213$ in the case of the extreme external even is presented. On the base of the meteorological monitoring of the locality the extreme snow load was defined for the return period $10^{4}$ years. There is showed summary of calculation models and calculation methods for the nonlinear analysis of the structural resistance in system ANSYS. The fragility curves of the critical structure elements were calculated using the FORM method.
\end{abstract}

\section{Introduction}

This paper deals with the resistance of the steel hale frame of the nuclear power plant (NPP) in locality Mochovce. The international organization IAEA in Vienna [1] set up the design requirements for the safety and reliability of the NPP structures.

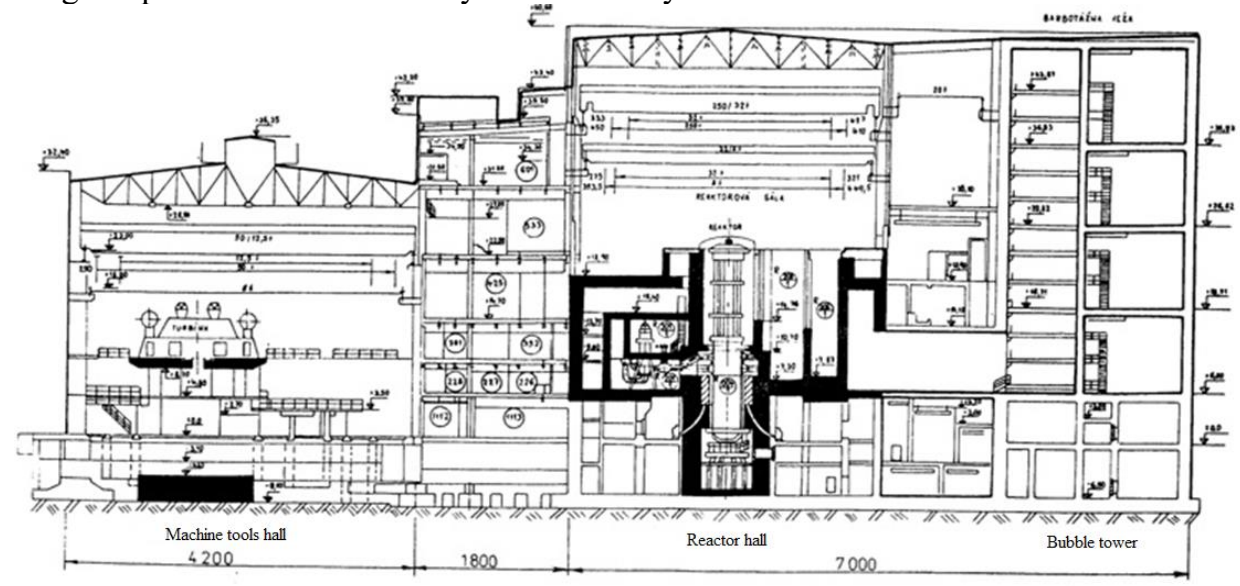

Fig. 1. Section plane of the NPP with reactor WWER440.

The extreme environmental events (e.g. wind, temperature, snow, explosion...) [1-9] are the important loads from the point of the NPP safety performance. The extreme snow loads

\footnotetext{
* Corresponding author: juraj.kralik@stuba.sk
} 
are defined with the probability of mean return period equal to one per $10^{4}$ years. The NRC [7] uses Probabilistic Risk Assessment (PRA) to estimate risk by computing real numbers to determine what can go wrong, how likely is it, and what are its consequences. Thus, PRA provides insights into the strengths and weaknesses of the design and operation of a nuclear power plant. The definition of the fragility curve of a nuclear power plant structures (NPP) generally represents a crucial step for the level 2 probabilistic safety assessment (PSA L2), where the probability of structure failure can be evaluated as the convolution of the fragility curve with the load curve. The assessment of the structural strength of the nuclear power plant has acquired even a greater importance in the framework of postFukushima stress tests where the assessment of the safety margin and off-design conditions $[8]$.
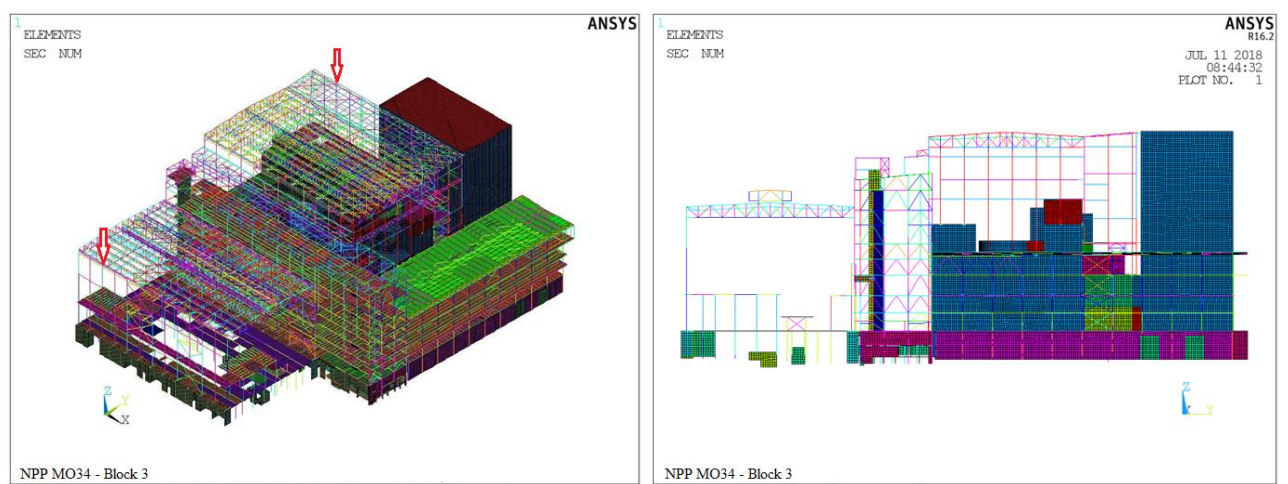

Fig. 2. Calculation model of the NPP buildings - machine tools hall, electrical buildings, reactor hall and bubble tower (critical frame is marked by red arrows).

The NPP buildings with the reactor VVER 440/213 [2] consist the turbine hall, middle building, reactor building and bubble condenser (Figure 1). The building of the power block was idealized with a FEM model consisting of 996917 elements with 444426 nodes (Figure 2) in program ANSYS.

\section{International safety requirements}

The safety requirements publication on safety of NPP design $[1,2,7]$ establishes following requirements:

"To ensure that the overall safety concept of defence in depth is maintained, the design shall be such as to prevent as far as practicable:

(1) challenges to the integrity of physical barriers,

(2) failure of a barrier when challenged,

(3) failure of a barrier as a consequence of failure of another barrier.

"All levels of defence shall be available at all times, although some relaxations may be specified for the various operational modes other than power operation."

The external event classification, if applied, does not imply different load levels for the external event scenarios and therefore the design of items classified for external events should refer only to the extreme values of design basic external events, or to a combination of these events where at least one of them is taken at, or close to, its extreme value. However, lower load intensities could be used in the design for two main reasons:

- for operational reasons, in order to identify an operational level for the plant, with associated requirements for shutdown, inspection and emergency procedures in case the load intensities exceed the threshold; 
- for load combinations with other design basis events, as a consequence of a probabilistic evaluation of the frequency of occurrence of some load combinations (e.g. including frequent wind, normal temperature and normal precipitation).

The influences of the external events to the NPP structures must be verified in accordance of the IAEA requirements [1] in three design levels (see Tab.1)

Table 1. Summary of technical characteristics and attributes of other external hazards.

\begin{tabular}{|l|l|}
\hline Element & Technical Characteristics and Attributes \\
\hline $\begin{array}{l}\text { External } \\
\text { Hazard }\end{array}$ & $\begin{array}{c}\text { - Another hazard analysis } \\
\text {-results in frequency of occurrence of other hazards at site based on } \\
\text { site-specific data } \\
\text { - reflects recent information uses historical data or a phenomenolo- } \\
\text { gical model, or a mixture of the two }\end{array}$ \\
\hline $\begin{array}{l}\text { External } \\
\text { Hazard } \\
\text { Fragility } \\
\text { Analysis }\end{array}$ & $\begin{array}{l}\text { - Fragility estimate } \\
\text { - Slant-specific, }\end{array}$ \\
\hline $\begin{array}{l}\text { External } \\
\text { Hazard } \\
\text { Plant }\end{array}$ & $\begin{array}{l}\text { - Hazard model } \\
\text { Response } \\
\text { Analysis } \\
\text { includes all important initiating events related to hazard analysed } \\
\text { external hazard and those that are not) that can lead to CDF }\end{array}$ \\
$\begin{array}{l}\text { - adapted from the internal events, at-power PRA model incorporates } \\
\text { unique aspects related to hazard analysed that are different from the } \\
\text { at-power, internal events PRA model. }\end{array}$ \\
\hline
\end{tabular}

\section{Methodology of the fragility analysis}

Most problems concerning the reliability of building structures [10-19] are defined today as a comparison of two stochastic values, loading effects $E$ and the resistance $R$, depending on the variable material and geometric characteristics of the structural element. The probabilistic definition of the reliability condition is of the form

$$
R F=g(R, E)=R-E \geq 0,
$$

where $g(R, E)$ is the reliability function.

The failure function $R F$ represents the condition (reserve) of the reliability, which can either be an explicit or implicit function of the stochastic parameters and can be single (defined on one cross-section) or complex (defined on several cross-sections, e.g., on a complex finite element model).

The most general form of the probabilistic reliability condition is given as follows:

$$
p_{f}=P(R-E<0) \equiv P(R F<0)<p_{d},
$$

where $p_{d}$ is the so-called design ("allowed" or "acceptable") value of the probability of failure.

From the analytic formulation of the probability density by the functions $f_{\mathrm{R}}(x)$ and $f_{\mathrm{E}}(x)$ and the corresponding distribution functions $\Phi_{\mathrm{R}}(\mathrm{x})$ and $\Phi_{\mathrm{E}}(\mathrm{x})$, the probability of failure can be defined in the general form: 


$$
p_{f}=\int_{-\infty}^{\infty} d p_{f}=\int_{-\infty}^{\infty} f_{E}(x) \Phi_{R}(x) d x=\int_{-\infty}^{\infty} \Phi_{E}(x) f_{R}(x) d x
$$

This integral can be solved analytically only for simple cases; in a general case it should be solved using numerical integration methods after discretization.

The index of reliability $\beta$ is used to define reliability of the structures on the base of the linearized failure function $g(X)$. In the case of the normal (e.g. lognormal) distribution we have following

$$
\beta=\mu_{R F} / \sigma_{R F},
$$

where $\mu_{R F}$ and $\sigma_{R F}$ are the mean values and the standard deviation of the reliability in the form

$$
\mu_{R F}=\mu_{R}-\mu_{E}, \quad \sigma_{R F}^{2}=\sigma_{R}^{2}+\sigma_{E}^{2}
$$

On base of the methodology of the hazard fragility analysis required by IAEA and NRC standards $[1,7]$, the parameter HCLPF (High Confidence of Low Probability of Failure) must be determined as the stochastic quantity defined in form of the distribution function. This parameter corresponds to the maximal accepted value of the extreme loads. These values are the input data for the complex risk analysis of the NPP safety.

The capacity reserve of the NPP structure can be determined from the reliability function (1) in following form

$$
g_{\lim }(R, E)=1-\left(E_{o}+\eta_{\lim } E_{E x L}\right) / R=0
$$

where the $E_{\mathrm{o}}$ is the action effects without the extreme load, $E_{\mathrm{ExL}}$ is the action of the extreme load, $\eta_{\text {lim }}$ is the factor of the extreme load capacity reserve. The parameter HCLPF can be expressed in following form related to equation (6)

$$
H C L P F_{E x L}=k_{D} \eta_{\lim } E_{E x L} \text { for } \eta_{\lim }=\left(R-E_{o}\right) / E_{E x L}
$$

where $k_{\mathrm{D}}$ is ductility factor in case when the $\eta_{\text {lim }}$ is determined from the linear analysis. The ductility factor presents the reserve of the total capacity of the statically indeterminate structures. The ductility factor $k_{\mathrm{D}}$ can be determined as the ratio of the load in case of the limit plastic and limit elastic state, as follows

$$
k_{D}=\eta_{p \cdot \lim } / \eta_{e . \lim }
$$

This methodology gives a good "estimate" of the structural resistance but does not accurately reflect the margin of resistance of the elements to the combined stress cases (e.g., bending and compression) because reliability functions have non-linear character .

A more accurate solution is the determination of the ultimate load by nonlinear analysis considering both material and geometric nonlinearity of the critical substructure of the structural system. In case of the incremental nonlinear solution we have

$$
\eta_{p . \lim }=\sum_{i=1}^{N} \Delta \eta_{i}
$$

The methodology of the external hazard fragility analysis requires [7] to define the parameter HCLPF considering the model and resistance uncertainties. If we propose the 
lognormal distribution function for the model and resistance uncertainties, then the parameter $H C L P F$ can be determined from the following relations

$$
H C L P F_{E x L . u}=k_{D} \eta_{\text {lim }} E_{E x L . m} \theta_{E} \theta_{R}
$$

where $E_{E x L . m}$ is the median value of the extreme action effects $E_{E x L}$ and structural resistance $R_{\mathrm{m}}, \theta_{E}$ is the lognormal density function with a unit median value and standard deviation $\beta_{E}, \theta_{R}$ is the lognormal density function with a unit median value and standard deviation $\beta_{R}$,

The value of the parameter $H C L P F_{E x L . u}$ for $95 \%$ probability of no-exceedance of the structural failure is determined from relation (10) in following form

$$
H C L P F_{E x L . u}=k_{D} \eta_{\text {lim }} E_{E x L . m} \exp \left\{-1.65\left(\beta_{E}+\beta_{R}\right)\right\}=k_{D} \eta_{\text {lim }} E_{E x L . m} \exp \left\{-2.3 \beta_{C}\right\},
$$

where $\beta_{C}=\sqrt{\beta_{R}^{2}+\beta_{E}^{2}}$ is the total standard deviation.

\section{Extreme snow load and load combinations}

The extreme snow load for the locality Mochovce was defined on the base of the last result of the SHMU investigations [20] in accordance of the Eurocode requirements [11, 21, 22].

The load on a structure due to the snowpack will depend on both snow depth and packing density. The maximal water depth by day in the winter time was defined for the return period $10^{4}$ years by the following values $-1.053 \mathrm{kPa}(5 \%), 1.281 \mathrm{kPa}(50 \%), 1.543 \mathrm{kPa}$ (95\%).

The characteristic value of the extreme snow load for $50 \%$ of no-exceedance at steel hall roof is

$$
p_{s k . m}=\mu_{i} \cdot C_{e} \cdot C_{t} \cdot p_{E s L . m}=1.025 \mathrm{kPa},
$$

where $\mu_{\mathrm{I}}=0.8$ is the snow load shape coefficient for leaning $\alpha \leq 30^{\circ} C_{\mathrm{e}}=1$ is the exposure coefficient, $C_{\mathrm{t}}=1$ is the thermal coefficient.
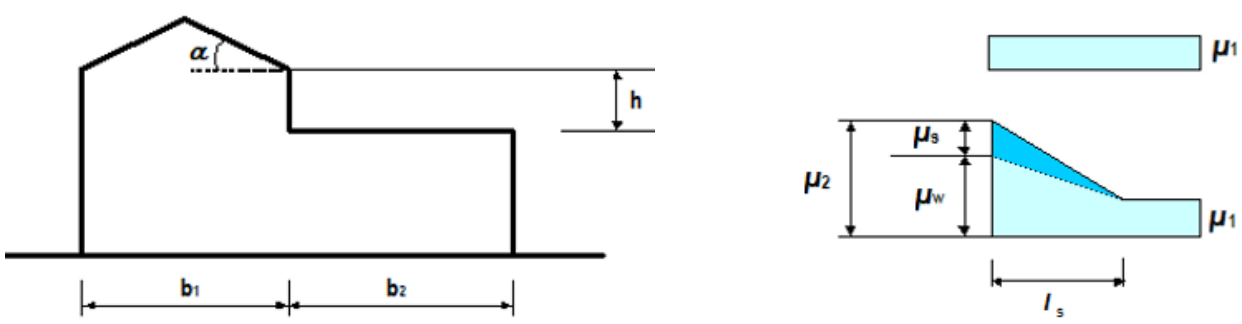

Fig. 3. Coefficients for snow load distribution on roof at contact with building wall.

In case of the snow load on machine tool roof at contact with the electrical building wall is necessary to consider the effect of the snow veil due to wind action in accordance with the EN 1991 [21]. These coefficients are following $\mu_{1}=0.8$ and $\mu_{2}=3.6$ and the characteristic loads on machine tool roof are as follows

$$
p_{s r 1 . m}=\mu_{1} C_{e} C_{t} p_{E s L . m}=1.025 \mathrm{kPa} \text { and } p_{s r 2 . m}=\mu_{2} C_{e} C_{t} p_{E s L . m}=4.612 \mathrm{kPa}
$$



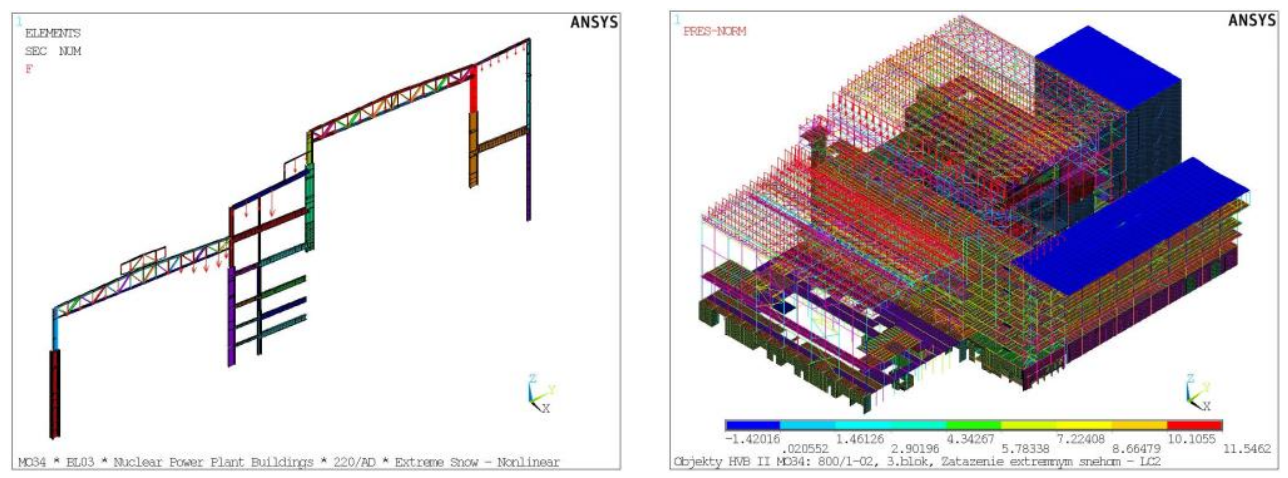

Fig. 4. FEM model with snow load, a) Critical frame of NPP buildings, b) 3D model of NPP.

The IAEA requirement [1] proposes to calculate the structure for situations - test conditions, design accident conditions, service conditions and the extreme environmental conditions. The load combination of the deterministic and probabilistic calculation is considered according to EN $1990[2,11]$ and IAEA [1] for the ultimate limit state of the structure as follows:

\section{- Deterministic method - extreme design situation}

$$
E_{d}=\gamma_{g} G_{k}+\gamma_{q} Q_{k}+\gamma_{a} A_{k}
$$

\section{- Probabilistic method-extreme design situation}

$$
E=G+Q+A_{E}=g_{\mathrm{var}} G_{k}+q_{\mathrm{var}} Q_{k}+a_{\mathrm{var}} A_{E . k},
$$

where $G_{k}$ is the characteristic value of the permanent dead loads, $Q_{k}$ - the characteristic (or median) value of the permanent live loads, $A_{k}$ - the characteristic value of the extreme loads, $\gamma_{g}, \gamma_{q}, \gamma_{a}$ are the loading parameters $\left(\gamma_{g}=\gamma_{q}=\gamma_{a}=1\right.$ for the extreme design situation), $g_{\text {var }}, q_{\text {var }}, a_{\text {var }}$ are the variable parameters defined in the form of the histogram calibrated to the load combination in compliance with Eurocode [2,11] and JCSS requirements [23].

Table 2. The histogrammes of the input data.

\begin{tabular}{|l|c|c|c|c|c|}
\hline & \multicolumn{2}{|c|}{ Quantities } & \multicolumn{3}{c|}{ Normalized histograms } \\
\hline $\begin{array}{l}\text { Input } \\
\text { data }\end{array}$ & $\begin{array}{c}\text { Characteristic } \\
\text { value }\end{array}$ & $\begin{array}{c}\text { Variable } \\
\text { value }\end{array}$ & Type & $\begin{array}{c}\text { Mean } \\
\mu\end{array}$ & $\begin{array}{c}\text { Deviation } \\
\sigma[\%]\end{array}$ \\
\hline Dead load & $G_{\mathrm{k}}$ & $g_{\mathrm{var}}$ & Normal & 1.0 & 10 \\
\hline Live load & $Q_{k}$ & $q_{\text {var }}$ & Gumbel & 0.6 & 25 \\
\hline Snow & $P_{\mathrm{k}}$ & $p_{\mathrm{var}}$ & Gumbel & 0.6 & 20 \\
\hline Strength & $F_{\mathrm{k}}$ & $f_{\text {var }}$ & Lognormal & 1.0 & 10 \\
\hline Action & $E_{\mathrm{k}}$ & $e_{\mathrm{var}}$ & Normal & 1.0 & 10 \\
\hline Resistance & $R_{\mathrm{k}}$ & $r_{\mathrm{var}}$ & Normal & 1.0 & 8 \\
\hline
\end{tabular}

The uncertainties of the input data - action effect and resistance are for the case of the probabilistic calculation of the structure reliability defined in JCSS [23] and Eurocode 1990 [11]. The input data are defined by the characteristic values and the variable coefficient (Table 2). 


\section{Nonlinear analysis}

The limit state of the critical steel frame was considered to utilise the geometric and material nonlinearity in program ANSYS $[2,3,24]$. The geometric nonlinearity is based on the theory of the large strain, which is often used for elastic-plastic elements. The elasticplastic model of steel material was taken in compliance with the Von Mises yield function. The Newton-Raphson iteration method to solve nonlinear equations was taken.

The motion vector $\{u\}$ is formulated by the position vectors for undeformed $\{X\}$ and deformed $\{x\}$ state

$$
\{u\}=\{x\}-\{X\}
$$

The computed strain increment $\left[\Delta \varepsilon_{n}\right]$ (or equivalently $\left\{\Delta \varepsilon_{n}\right\}$ ) can be added to the previous strain $\left\{\varepsilon_{n-1}\right\}$ to obtain the current total Hencky strain. The strain increment is also computed from the midpoint configuration.

$$
\left\{\Delta \varepsilon_{n}\right\}=\left[B_{1 / 2}\right]\left\{\Delta u_{n}\right\},
$$

where $\left\{\Delta u_{n}\right\}$ is the displacement increment over the time step and $\left[B_{1 / 2}\right]$ is the straindisplacement relationship evaluated at the midpoint geometry. This method is an excellent approximation to the logarithmic strain if the strain steps are less than $\sim 10 \%$. This method can be used by the standard 2-D and 3-D solid and shell elements.

For the case of nonlinear materials, the stress increment can be computed via the elastic stress-strain relations

$$
\{d \sigma\}=\left[D_{e l}\right]\left\{d \varepsilon^{e l}\right\}
$$

where $\left[D_{e l}\right]$ is the stress-strain matrix and the elastic strain is defined in the form of:

$$
\left\{d \varepsilon^{e l}\right\}=\{d \varepsilon\}-\left\{d \varepsilon^{t h}\right\}-\left\{d \varepsilon^{p l}\right\}
$$

where $d \varepsilon^{e l}$ is an increment of elastic strain vector, $d \varepsilon$ - an increment of total strain vector, $d \varepsilon^{\text {th }}$ - an increment of thermal strain vector, $d \varepsilon^{p l}$ - an increment of plastic strain vector.

The incremental theory of plasticity provides a mathematical relationship that characterizes the elastic-plastic response of materials. There are three ingredients in the rate-independent plasticity theory: the yield criterion, flow rule and the hardening rule.

The increment of the plastic strain results from the flow rule by Drucker (condition of positive plastic work)

$$
\left\{d \varepsilon^{p l}\right\}=d \lambda\left\{\frac{\partial Q}{\partial \sigma}\right\}
$$

where $d \lambda$ is plastic multiplier (which determines the amount of plastic straining) and $Q$ is plastic potential (which determines the direction of plastic straining). The plastic multiplier $d \lambda$ express from consistency condition of yield function $d F(\sigma, \kappa, \alpha)=0$

$$
d \lambda=\frac{\left\{\frac{\partial F}{\partial \sigma}\right\}^{T}\left[D_{e l}\right]\{d \varepsilon\}}{-\frac{\partial F}{\partial \kappa}\{\sigma\}^{T}\left\{\frac{\partial Q}{\partial \sigma}\right\}-C\left\{\frac{\partial F}{\partial \alpha}\right\}^{T}\left\{\frac{\partial Q}{\partial \sigma}\right\}+\left\{\frac{\partial F}{\partial \sigma}\right\}^{T}\left[D_{e l}\right]\left\{\frac{\partial Q}{\partial \sigma}\right\}}
$$


The yield function $F($.$) defines the state, when the plastic strain \varepsilon^{p l}$ is started. Generally, the yield criterion can be defined as follows

$$
F(\sigma, \kappa, \alpha)=0
$$

where $\kappa$ is the hardening parameter (plastic work) and $\alpha$ is the back stress (location of the centre of the yield surface). The yield function was taken by Von Mises for the steel material in following form of Von Mises yield function

$$
F(\sigma, \kappa, \alpha)=\sqrt{3 J_{2}}-\sigma_{y}(\kappa)
$$

where $J_{2}$ the second invariant of the stress tensor is, $\sigma_{y}(\kappa)$ is the yield parameter.

The nonlinear material model is defined as multilinear isotropic hardening material model. The steel frame is made from steel of type S235 :

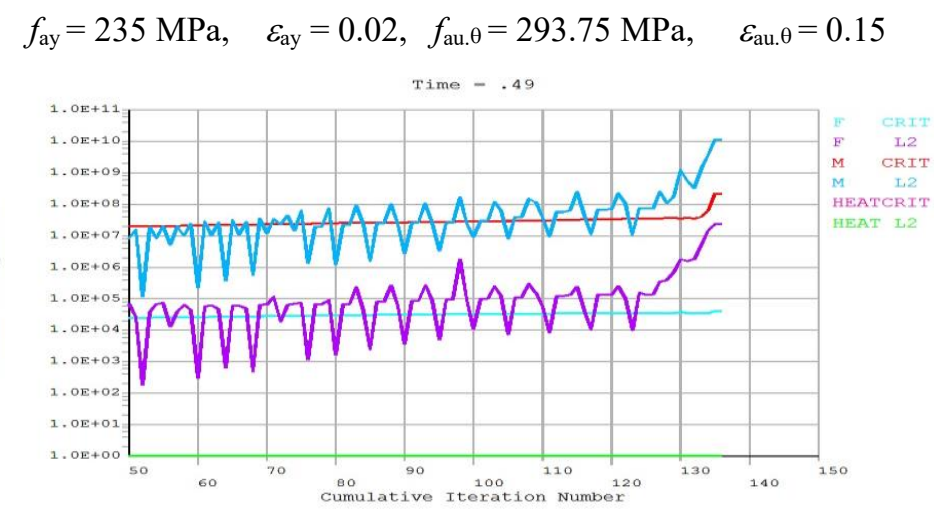

Fig. 5. Convergence of the nonlinear analysis.

On the base of the linear analysis of the 3D FE model under extreme snow load the critical frame was determined. 2D FE model of the critical frame was determined from the 3D FE model using the substructure method (see fig.4 and 6).

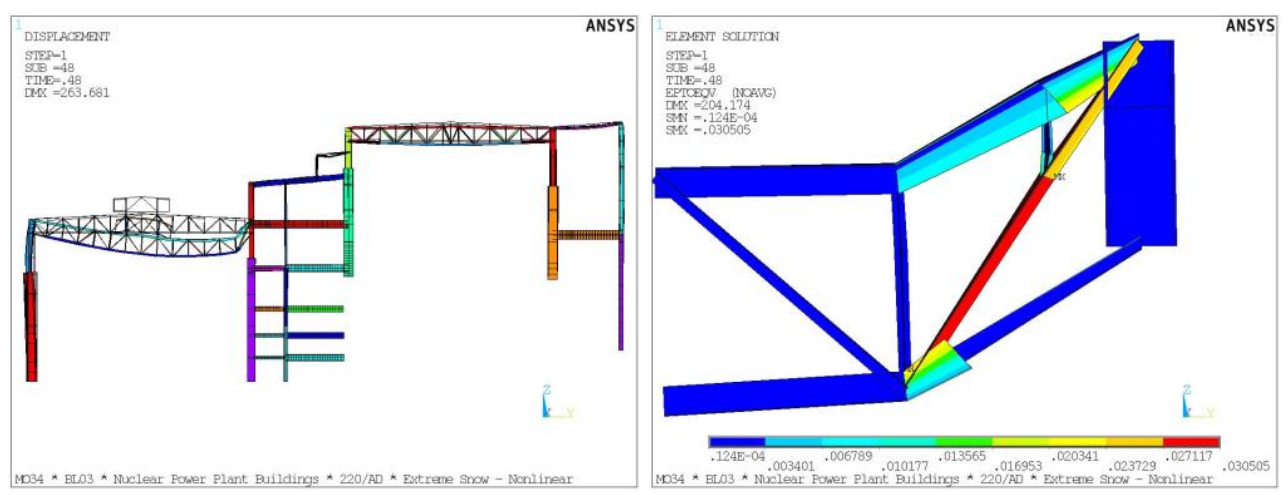

Fig. 6. Deformed shape of the critical frame under extreme snow loads for $p_{\text {su.m }}=3.545 \mathrm{kPa}$.

The nonlinear analysis of the critical frame in modulus 220/A-D of NPP buildings was realised using the Newton-Raphson method in 136 iteration steps (see fig. 5). The failure snow load determined from the nonlinear analysis is following (see fig. 6) 


$$
p_{\text {su. } . m}=3.459 p_{\text {sk.m }}=3.545 \mathrm{kPa}
$$

The results of the nonlinear analysis are presented in the table 3. There are the results of the load limit state for the elastic and plastic state for the median and design value of loads.

Table 3. Maximal equivalent stress from the nonlinear analysis of the critical frame.

\begin{tabular}{|c|c|c|c|c|}
\hline Limit & Load & Load & \multicolumn{2}{|c|}{$p_{\text {s.lim }}[\mathrm{kPa}]$} \\
\cline { 4 - 5 } state & factor $\eta$ & increment $\Delta \mathrm{p}_{\mathrm{s}}$ & $50 \%$ & $95 \%$ \\
\hline Elastic & 5 & 0.25 & 1.846 & 1.565 \\
\hline Plastic & 5 & 0.48 & 3.545 & 3.006 \\
\hline
\end{tabular}

\section{High confidence of low probability of failure}

We consider the median value of the boundary effect of the load $-p_{\mathrm{sm}}=2.40 \mathrm{kPa}$, logarithmic standard deviation of the load effect $\beta_{E}=0.1$ and resistance $\beta_{R}=0.08$ in accordance with the standard JCSS [20]. Then the parameter HCLPF for 95\% probability of noexidance can be determined considering lognormal distribution in relations (11) as follows

$$
\beta_{c}=\sqrt{\beta_{E}^{2}+\beta_{R}^{2}}=0.13, \text { and } H C L P F_{E s L . u}=p_{s u . m} \exp \left(-2.33 \beta_{c}\right)=1.78 \mathrm{kPa}
$$

In case of extreme load, it is possible to consider plastic reserve of steel element according to recommendations $[1,2]$. Then we get the value of the ultimate limit for the failure of the structure for the ductility factor $k_{\mathrm{D}}=1.25$ following

$$
H C L P F_{E s L . d}=k_{D} p_{s u . m} \exp \left(-2.33 \beta_{c}\right)=2.23 \mathrm{kPa}
$$

\section{Fragility curves of the structure resistance}

The probability of the frame failure was determined by the probabilistic analysis by the simulation in LHS method using program FReET [16].
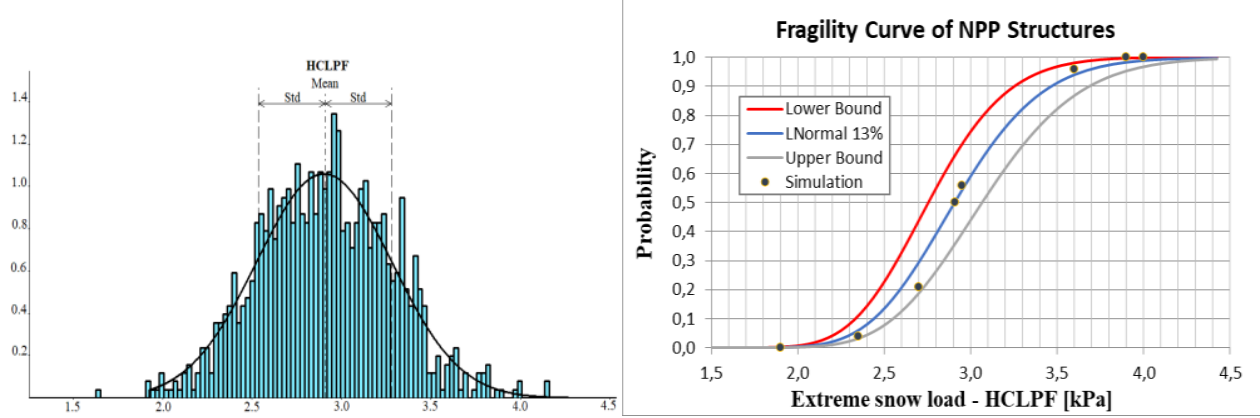

Fig. 7. The simulated density function and idealized fragility curves of the steel frame.

The uncertainties of the input data - action effect and resistance are for the case of the probabilistic calculation of the structure reliability considered in accordance with JCSS [23]. The input data are defined by the characteristic values and the variable coefficient (Tab.2). The probabilistic density of the failure function of the steel frame for the extreme snow is presented in Fig.7 as the value of the parameter HCLPF 


$$
H C L P F_{E s L . d}(L H S)=2.294 k P a
$$

\section{Conclusion}

This paper presents the reliability analysis of the steel hall frame resistance due to extreme snow loads [15]. The extreme loads were defined for mean return period equal to one per $10^{4}$ years in accordance of the IAEA requirements for NPP structures [5 and 20]. The geometric and material nonlinearity were considered. The deterministic and probabilistic analysis of the structure failure was investigated. The limit state (frame collapse) was obtained from deterministic analysis for the factor for extreme snow load. The probability of failure was calculated on program FReET using LHS method [17]. The probability of failure value is lower than $10^{-6}$. The idealized fragility curves were calculated for the lognormal distribution with lower and upper boundary equal to standard deviation. This paper presented the methodology and application of the probabilistic nonlinear analysis of NPP structures safety under the extreme environment loads.

This article was created with the support of the Ministry of Education of Grant Agency of the Slovak Republic (grant VEGA No. 1/0265/16).

\section{References}

1. IAEA Safety Standards, No. SSG-18, Vienna (2011)7

2. J. Králik, Safety and Reliability of NPP, Ed. STU Bratislava, 305 p. (2009)

3. J. Králik, Reliability Analysis of Structures, Ed. STU Bratislava, 143 pp. (2009)

4. J. Králik, Applied Mechanics and Materials, Vol. 390, pp.172-177, DOI: 10.4028/ www.scientific.net/AMM.390.172, (2013)

5. A. B. Nikolic, Z.S. Janda, Monograph, INTECH, ISBN 978-953-51-3357-5 (2017)

6. Z. Kovacs, Probabilistic Safety, Springer, DOI10.1007/978-3-319-08548-7 (2014)

7. NRC, $R G$ 1.200, U.S. NRC, Washington, DC. (2009)

8. NRA SR, The stress tests for NPP Slovakia, Bratislava, september (2011)

9. V. Salajka, P. Hradil, J. Kala, Proc. ICETI 2012, Kaohsiung, Taiwan, pp.4 (2012)

10. A. Haldar, S. Mahadevan, Monograph, John Wiley \& Sons, New York (2000)

11. M. Holicky, Reliability analysis for structural design, SUN PRESS, (2009)

12. R. E. Melchers, Structural Reliability, John Wiley \& Sons, Chichester, U.K. (1999)

13. M. Krejsa, et al., ICASP 9, San Francisco, USA, July 6-9, pp. 91-96 (2003)

14. M. Krejsa et al., Journal of Multiscale Modelling, Vol. 6, No. 2 (2015)

15. M. Krejsa, R. Čajka, Applied Mechanics and Materials Vols. 501-504 pp 592-598, TTP, Switzerland, DOI:10.4028/www.scientific.net/AMM.501-504.592 (2014)

16. D. Novák et al. Proc. ICASP 9, San Francisco, USA, July 6-9, pp. 91-96 (2003)

17. Z. Kala, Engineering Structures, 33, 8, pp.2342-2349, (2011)

18. Z. Kala, J. Kala, AIP Proc. 1479 (1), pp. 2074-2077, DOI: 10.1063/1.4756598 (2012)

19. P. Suchardová, O.Sucharda, Applied Mechanics and Materials, 357-360, pp. 28762880, DOI: 10.4028/www.scientific.net (2013)

20. SHMU, Final report for locality Mochovce, Bratislava, january (2012)

21. EN 1991, Actions on structures - Part 1-3: General actions Snow loads. (2003) 
22. ISO 2394, General principles on reliability for structures, ISO Switzerland (2015)

23. JCSS-OSTL/DIA/VROU-10-11-2000, http://www.jcss.ethz.ch. (2000)

24. Kohnke, ANSYS, Inc. Theory Manual. Ed. SAS IP, Inc. (1994) 